\title{
What are the safety implications of dynamic fire behaviours?
}

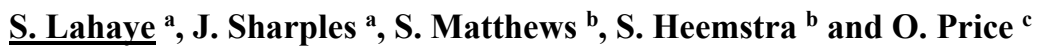 \\ a School of Physical, Environmental and Mathematical Sciences, University of New South Wales Canberra, \\ ACT 2600, Australia. \\ ${ }^{b}$ New South Wales Rural Fire Service, 15 Carter St Lidcombe, NSW 2141, Australia. \\ ${ }^{c}$ Centre for Environmental Risk Management of Bushfires, University of Wollongong, NSW 2522, Australia. \\ Email: s.lahaye@adfa.edu.au
}

\begin{abstract}
Many firefighters in the world have been injured or killed due to a forest fire entrapment, caught by the fire heat or smoke. Some case studies have pointed out that dynamic fire behaviour may have played a role. We investigate here how changes in wind direction, channelling (i.e. vorticity-driven lateral spread on a leeward slope) and long distance spotting could contribute to entrapments through a process model, simplified in Figure 1. There are three situations likely to entrap firefighters:

- S1. Facing a violent fire front either because of a change in wind direction or not

- S2. Fire channelling, i.e. fire developing an atypical lateral spread

- $\quad$ S3. Fire developing at a long distance because of mass spotting.
\end{abstract}

We review fire agencies archives in Australasia and Europe from 1979 to 2017 and retrieve 106 entrapments, investigating weather, terrain and location of fire front during entrapment. We also compare the Australasian subset with fires without entrapment using a binomial regression function.

In Australia, changes in wind direction induced by cold front passes is the main factor contributing to entrapment. These sudden changes in wind direction switch long smooth burning flanks of fire in violent fronts and lead to S1 situations. S2, sudden lateral spread, occurs in rough terrain. There, leeward slopes may generate channelling, causing entrapment several hundred meters far away from the fire flank. S3 appears when fire danger index reaches highest values. When fuel drought combines with adverse weather conditions, mass spotting propagates fire at long distance. Then, firefighters may be entrapped whatever the terrain.

This work improves our understanding of the process from dynamic fire behaviour to firefighter entrapment. Identifying three different situations, the model should help fire agencies to adapt their safety warnings regarding the local daily conditions.

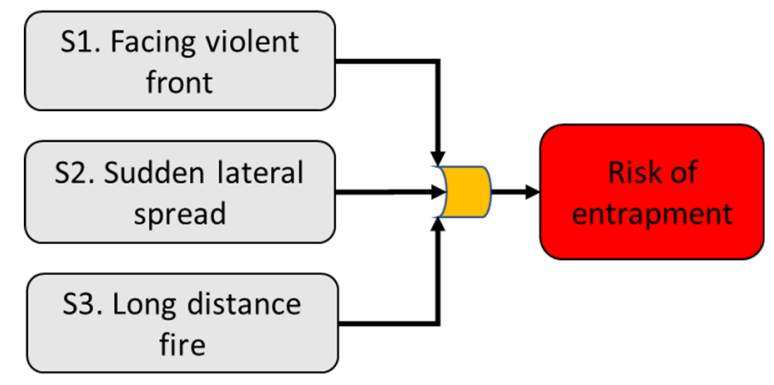

Figure 1. Simplified process model of entrapments.

Keywords: $\quad$ Entrapments, firefighters' safety, wildfires, extreme behaviours 


\section{INTRODUCTION}

In wide areas of Northern America, Southern Australia or Mediterranean Europe adverse weather conditions and drought may induce very large and destructive fires. Firefighters have developed first massive attack strategies to protect endangered population and assets. Therefore, they are highly exposed to fire entrapments, i.e. to be caught by the fire heat or smoke.

From 1910 to 2006, 900 firefighters perished in the United States, including 411 from entrapment (Mangan, 2007). In Europe, 521 fatalities, both civilians and firefighters, were non-exhaustively counted between 1980 and 2007 (Viegas et al., 2009). In Australia, 733 civilians and 92 firefighters died during bushfires between 1901 and 2011 (Blanchi et al., 2014).

To improve safety, fire agencies have focused on upgrading their vehicles and equipment. Safety procedures have also evolved. Reviewing some case studies, Cheney et al. (2001) defined the concept of "Dead-Man Zone", intended to warn against entrapment due to a sudden change of wind direction. The concept has been widely disseminated in bushfire fighting training material in Australia. Nevertheless, selecting the appropriate technics and tactics requires a good understanding of fire behaviours likely to cause the risk.

Sharples et al. (2016) described different dynamic fire behaviours that contribute to extreme bushfires: fire eruption, fire channelling, change in wind direction and mass spotting.

As Mc Rae and Sharples (2013) described a process model for extreme bushfires, we suggest that there may be a process model for dynamic fire behaviours causing firefighter entrapments. We investigated in this study entrapments over the last forty years across Europe and Australasia to test the model.

\section{PROCESS MODEL}

We presume that firefighters are entrapped because of one of the following situations (Figure 2):

- S1. Facing a violent fire front either because of a change in wind direction or not

- $\quad$ S2. Fire channelling, i.e. fire developing an atypical lateral spread

- S3. Fire developing at a long distance because of mass spotting.

It is worth noting that dynamic fire behaviours may also interact and escalate the risk of entrapment.

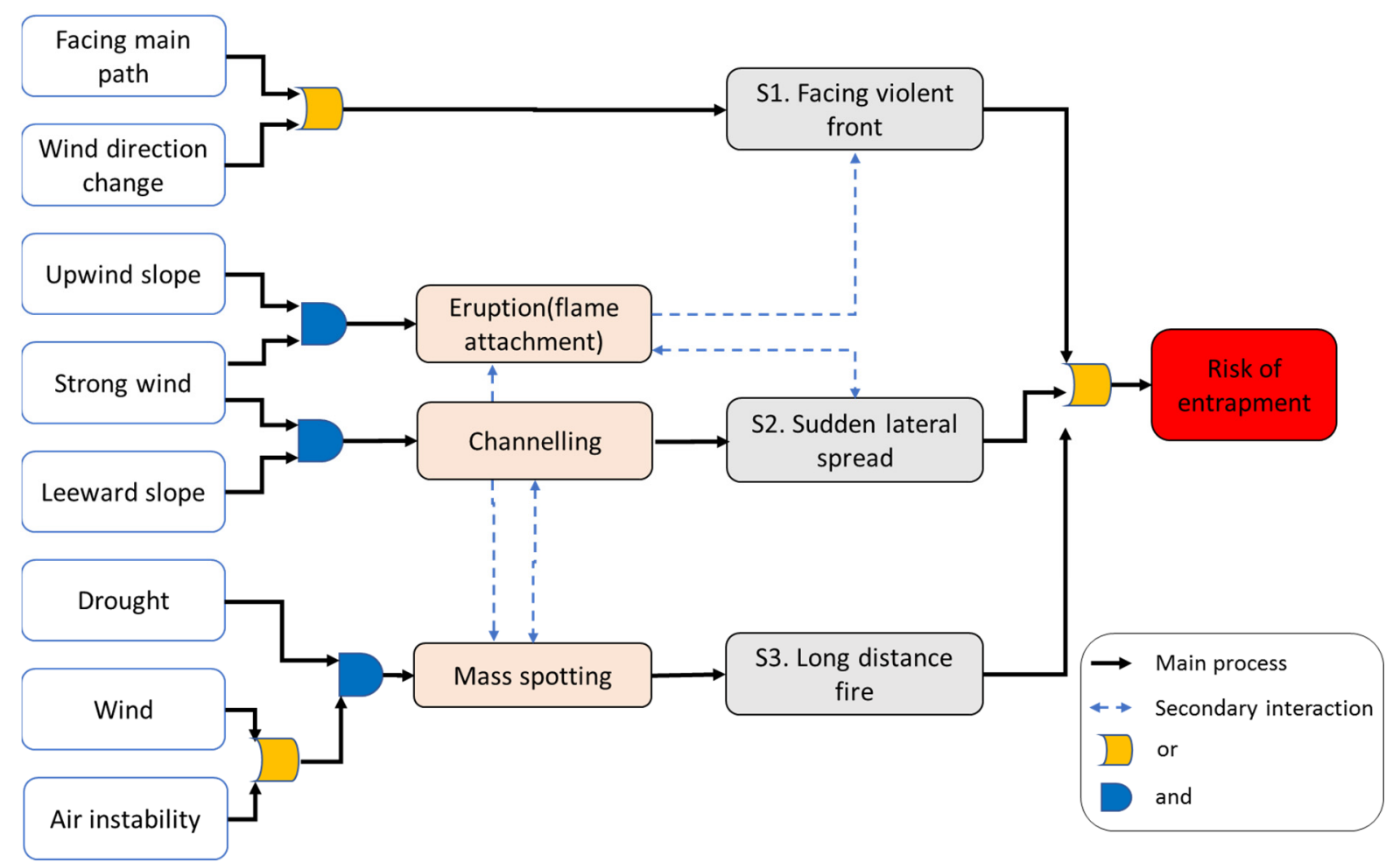

Figure 2. Process model of entrapments. 


\section{REVIEW OF 106 ENTRAPMENTS}

We analysed two sets of data: 60 entrapments collected by Lahaye et al. (2016) in Europe from 1979 to 2017 (EUR) and 46 entrapments investigated in Australia and New Zealand (AU) during the same period (Figure 3).

There is no official database of fire entrapments either in European countries, or in Australia. However, agencies or state authorities have produced investigation reports or communications after the most serious accidents in recent years. We analysed both published papers and fire service internal reports. The 46 cases retrieved in AU came from five states and the 60 in EUR from five countries (Table 1). Together, they represent 138 deaths and 134 injured firefighters.

(a)
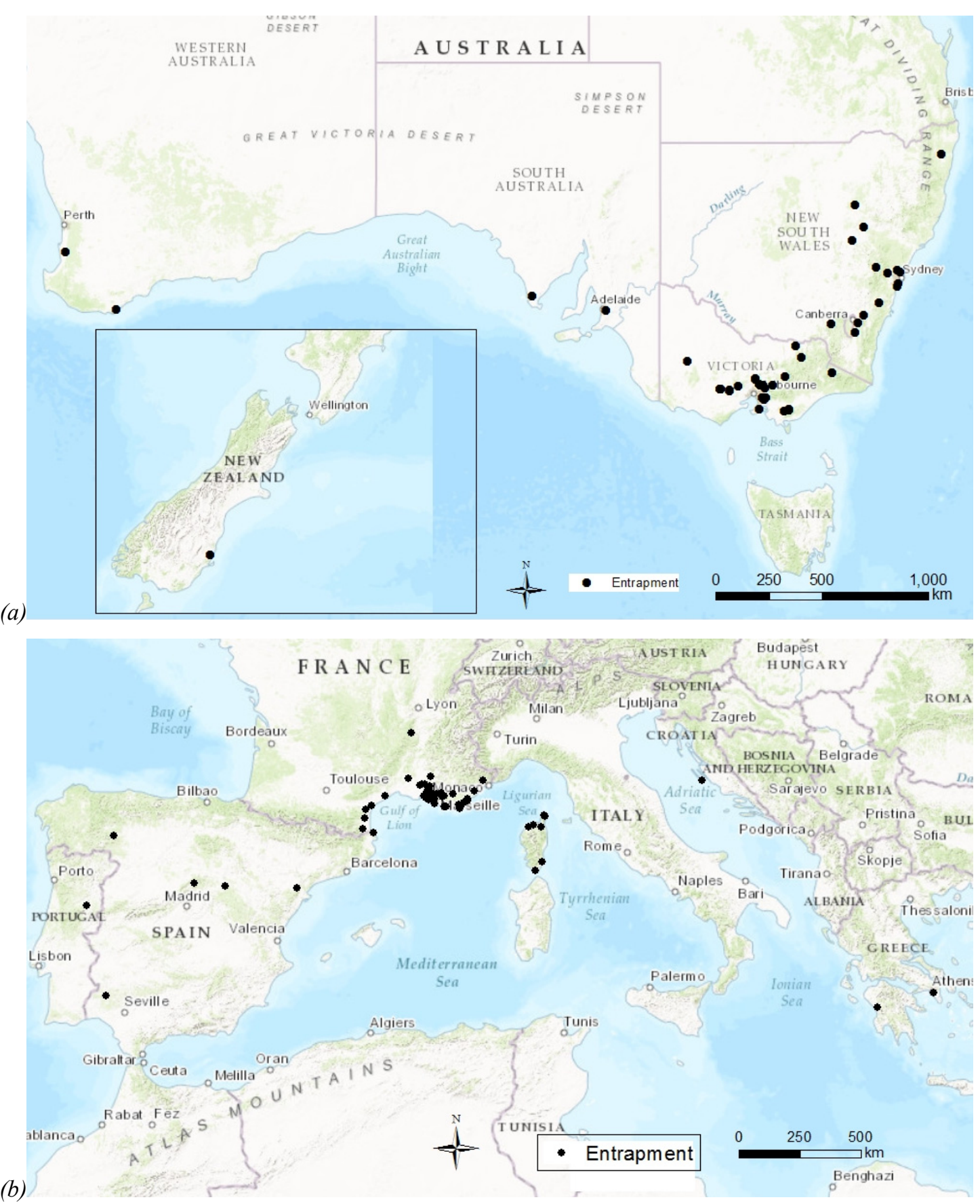

Figure 3. Location of entrapments in (a) Australasia and (b) Europe. (map support ESRI. ArcGIS 10.4) 
Lahaye et al., What are the safety implications of dynamic fire behaviors?

Table 1. Distribution of entrapments across states.

\begin{tabular}{llcccc}
\hline & State & $\begin{array}{c}\text { Nb. of } \\
\text { Entrapments }\end{array}$ & Fatalities & Injured & $\begin{array}{c}\text { Lost } \\
\text { vehicles }\end{array}$ \\
\hline AU & New South Wales (NSW) & 15 & 15 & 26 & 7 \\
& Victoria (VIC) & 26 & 20 & 44 & 12 \\
& Southern Australia (SA) & 2 & 3 & 6 & 2 \\
& Western Australia (WA) & 2 & 1 & 3 & 3 \\
& New Zealand (NZ) & 1 & 0 & 4 & 0 \\
\hline Subtotal AU & 46 & 39 & 83 & 24 \\
\hline EUR & France (FR) & 51 & 27 & 48 & 43 \\
& Spain (SP) & 5 & 26 & 2 & 5 \\
& Portugal (PO) & 1 & 6 & 0 & 0 \\
& Croatia (CR) & 1 & 12 & 1 & 0 \\
& Greece (GR) & 2 & 28 & 0 & 2 \\
\hline Subtotal EUR & 60 & 99 & 51 & 50 \\
\hline Total & & $\mathbf{1 0 6}$ & $\mathbf{1 3 8}$ & $\mathbf{1 3 4}$ & $\mathbf{7 4}$ \\
\hline
\end{tabular}

For each entrapment, we investigated any change in wind direction and calculated a weather danger index, relating to drought, windspeed, temperature and relative humidity. We also investigated the terrain, represented by both the slope and a larger scale index of ruggedness.

\section{WIND DIRECTION CHANGES IN AUSTRALIA}

Cold front passes are responsible for challenging changes in wind direction during fires in Australia (Mills, 2005). They may change smooth burning flanks in active fire heads. To investigate the contribution of this driver in the 46 entrapments in AU we generated a comparative set of 46 fires without entrapment, retrieved from historical databases of fire agencies. We used the generalized linear model (glm) function of R software to build a binomial logistic regression model of entrapment probability. Figure 4 shows that change in wind direction is the main driver of entrapment in AU. $41 \%$ of entrapments happened within one hour after such a change. Forest Fire Danger Index (FFDI) is also a driver of entrapment. Slope plays a less significant role.

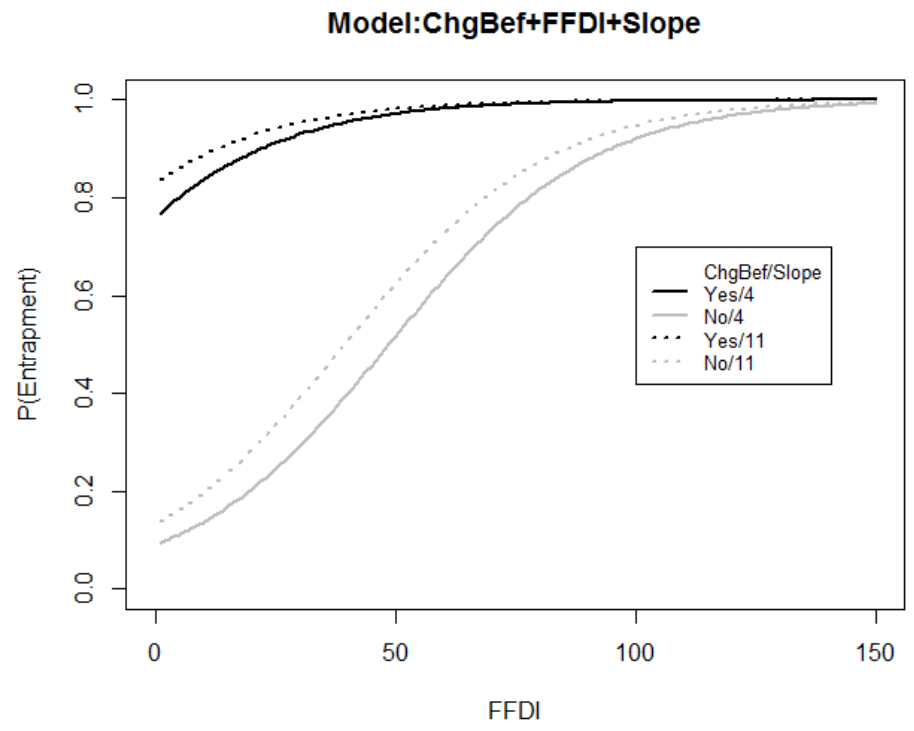

Figure 4. Regression modelling of entrapment probability regarding FFDI with (black lines) or without (grey lines) a change in wind direction. Full lines correspond to a slope of $4^{\circ}$ and dot lines to a slope of $11^{\circ}$.

\section{FIRE CHANNELING AND LONG DISTANCE SPOTTING}

$\mathrm{S} 1$ is made of both changes in wind direction and firefighters facing the initial front of fire, often to protect threatened assets. To determine the role played by S2 and S3 in entrapments, we investigated the final size of fire and the location of fire front during each of the 106 entrapments. We firstly created S3 class with fires larger than 5000 ha, assuming that very large and extreme fires are associated with conditions prone to mass spotting and long distance propagation. Then we created S2 class with entrapments of firefighters on flank of 
fire. S1 class was made of the remaining cases. The repartition of entrapments between classes is: $\mathrm{S} 1-52 \%, \mathrm{~S} 2-$ $20 \%, \mathrm{~S} 3-28 \%$.

Figure 5 displays weather danger index and terrain conditions for each of the three classes. We used Dowdy et al. (2010) equation to extrapolate an estimated Fire Weather Index (FWI) from FFDI in Australia:

$$
\begin{aligned}
& \text { If FFDI } \leq 20 \text {, then FWI }=2.8 F F D I-0.3 \\
& \text { If } \mathrm{FFDI}>20 \text {, then } \mathrm{FWI}=2.2 \mathrm{FFDI}+10.8
\end{aligned}
$$

S3 entrapments occur with high value of FWI $\left(1^{\text {st }}\right.$ quartile $\left.>69\right)$ while slope is moderate $\left(3^{\text {rd }}\right.$ quartile $\left.<11^{\circ}\right)$ and ruggedness mostly ranges from 128 ( $1^{\text {st }}$ quartile) to 267 ( $3^{\text {rd }}$ quartile). When the weather danger is conducive to extreme fires, long distance spotting can entrap firefighters whatever the terrain. Slope for S2 entrapments, with a $3^{\text {rd }}$ quartile $<18^{\circ}$, is generally under the thresholds for fire eruption or channelling established around $25^{\circ}$ by Sharples et al. (2014). However, ruggedness for S2 corresponds to rough terrain, ranging from 157 ( $1^{\text {st }}$ quartile) to 506 ( $3^{\text {rd }}$ quartile). This figures that dynamic fire behaviours such as channelling may initiate beyond the local slope and cause entrapments several hundred meters far away from the fire flank.
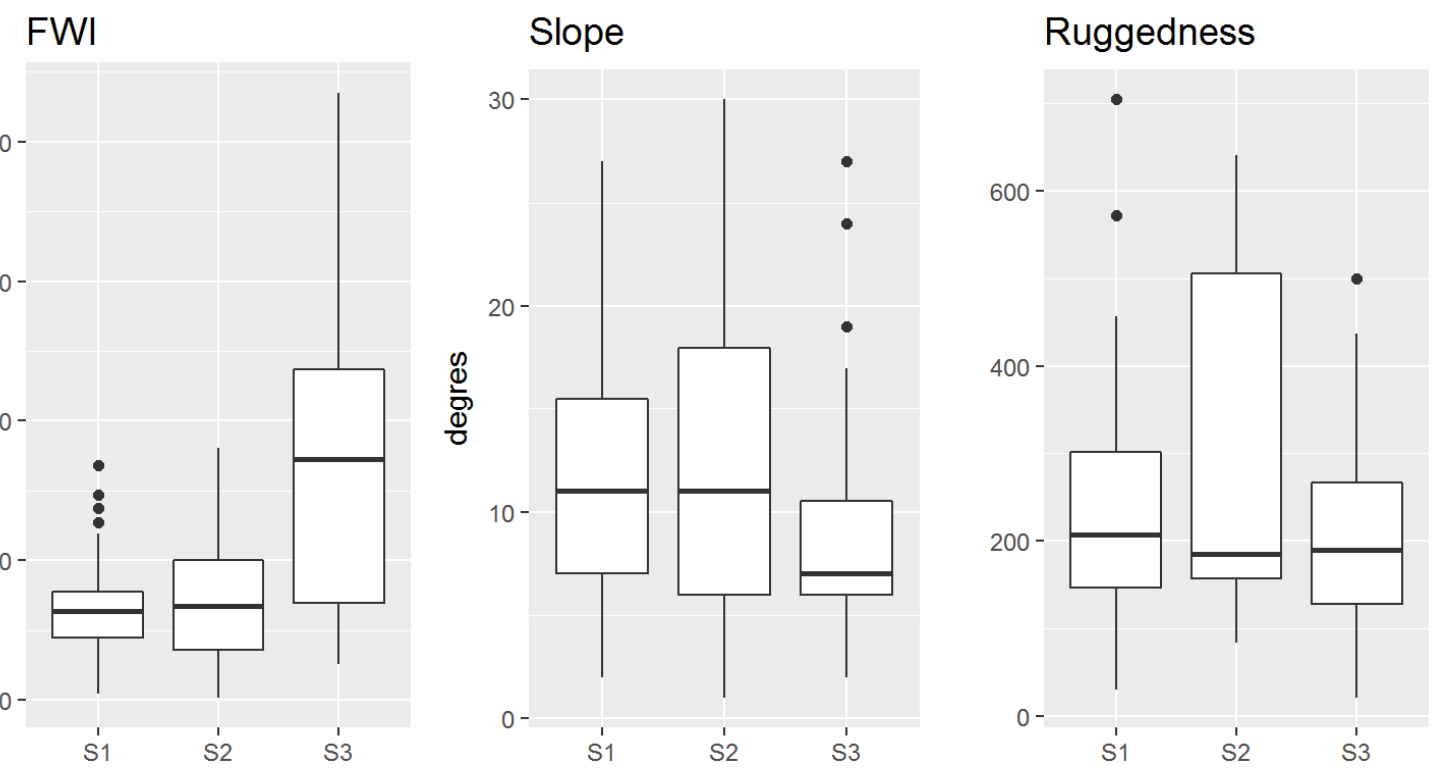

Figure 5. Comparative repartition of FWI, slope and ruggedness between the three classes of entrapments.

\section{CONCLUSION}

There are three different situations where firefighters are entrapped. The first situation corresponds to firefighters facing a violent fire front. In Australia, sudden changes in wind direction often results in this dangerous situation. The second situation characterizes fire flanks producing a violent lateral run, supposedly issued by fire channelling. The third situation occurs in the most adverse weather conditions with extreme fires generating mass spotting able to entrap firefighters at a long distance.

This paper shows that dynamic fire behaviours have significant safety implications, represented by a process model. The model may evolve as our understanding of dynamic fire behaviours improves and safety procedures for firefighters should benefit from the researches.

\section{REFERENCES}

Blanchi, R., J. Leonard, K. Haynes, K. Opie, M. James, \& F. D. de Oliveira. (2014). Environmental circumstances surrounding bushfire fatalities in Australia 1901-2011. Environmental Science \& Policy, 37, 192-203.

Cheney, P., J. Gould, \& L. McCaw. (2001). The dead-man zone-a neglected area of firefighter safety. Australian Forestry, 64(1), 45-50. 
Lahaye et al., What are the safety implications of dynamic fire behaviors?

Dowdy, A. J., G. A. Mills, K. Finkele, \& W. de Groot. (2010). Index sensitivity analysis applied to the Canadian Forest Fire Weather Index and the McArthur Forest Fire Danger Index. Meteorological Applications, 17(3), 298-312. doi:10.1002/met.170

Lahaye, S., T. Curt, \& C. Hely. (2016). Which configurations cause entrapment risk? Paper presented at the 5th International Fire Behaviour and Fuels Conference, Melbourne, Australia.

Mangan, R. J. (2007). Wildland firefighter fatalities in the United States: 1990-2006 (NWCG PMS 841 Technical report). Boise, ID, USA.

Mc Rae, R. H. D., \& J. Sharples. (2013). A process model for forecasting conditions conducive to blow-up fire events. Paper presented at the MODSIM2013, 20th International Congress on Modelling and Simulation, Adelaide, Australia

Mills, G. A. (2005). On the sub-synoptic scale meteorology of two extreme fire weather days during the Eastern Australian fires of January 2003. Australian Meteorological Magazine, 54, 265-290.

Sharples, J., G. J. Cary, P. Fox-Hughes, S. Mooney, J. P. Evans, M.-S. Fletcher, . . P. Baker. (2016). Natural hazards in Australia: extreme bushfire. Climatic Change, 139(1), 85-99. doi:10.1007/s10584-0161811-1

Sharples, J., C. Simpson, J. P. Evans, \& R. H. D. Mc Rae. (2014). Threshold behaviour in dynamic fire propagation. Paper presented at the Bushfire and Natural Hazards CRC \& AFAC Conference, Wellington, New Zealand, 2 September 2014.

Viegas, D. X., A. Simeoni, G. Xanthopoulos, C. Rossa, L. Ribeiro, L. Pita, . . D. Caballero. (2009). Recent Forest Fire Related Accidents in Europe. Luxembourg: European Commission. 